\title{
WAVE STRUCTURE INTERACTION: ROLE OF ENTRAPPED AIR ON WAVE IMPACT AND UPLIFT FORCES
}

\author{
M. Bozorgnia ${ }^{1}$, Jiin-Jen Lee ${ }^{1}$ and Frederic Raichlen ${ }^{2}$
}

In present paper, a numerical wave load model based on compressible two-phase Navier Stokes type equations is used to evaluate hydrodynamic forces exerted on I-10 bridge across Mobil Bay which was extensively damaged during Hurricane Katrina. The volume of fluid method (VOF) is used in the model to describe dynamic free surface which is capable of simulating complex discontinuous free surface associated with wave-deck interactions. Special emphasis was put on investigating the role of entrapped air on hydrodynamic forces exerted on bridge superstructure. Numerical simulation results indicate that air entrapment can significantly amplify uplift forces applied to the bridge superstructure. To mitigate hydrodynamic forces, effectiveness of airvents is investigated. It has been shown that airvents can significantly damp out wave energy and can effectively reduce uplift forces.

Keywords: wave structure interaction; effect of air entrapment and entrainment on hydrodynamic forces; air vents; bridge deck retrofitting.

\section{INTRODUCTION}

The impact of hurricanes on many aspects of the civil engineering infrastructure can be devastating. Hurricane Katrina has been reported to be the costliest natural disaster in the recent history of the United States. The property damage from Hurricane Katrina well exceeded 100 billion dollars.

Many low-lying short and medium span bridges did not withstand the storm surge and wave actions that accompanied Hurricane Katrina. The cost of rebuilding all the coastal bridges damaged by Hurricane Katrina (2005) exceeds 1 billion U.S. dollars (TCLEE 2006). Figure 1 shows some of the major bridges damaged during Hurricane Ivan and Katrina.

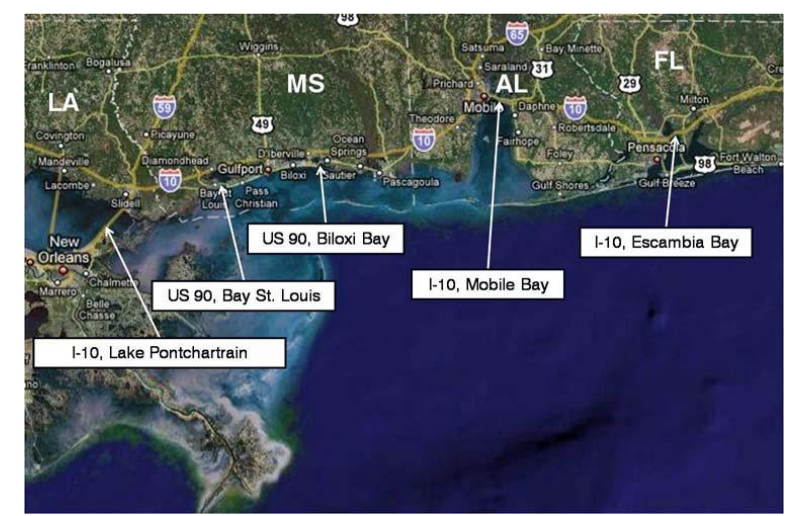

Figure 1. Major highway bridges damaged along the U.S. Gulf coast during Hurricanes Ivan and Katrina.

The objective of this paper is to apply a two phase compressible numerical model to investigate the full scale dynamic loading of uplift and impact wave forces on a bridge superstructure similar to I-10 bridge across Mobil Bay. Also the amplification of hydrodynamic forces due to air entrapment is evaluated.

In the following sections, the numerical wave load model is described and validated by experimental data. Following model validation, the numerical model is used to calculate hydrodynamic forces applied to the I-10 bridge across Mobil Bay. Next, to evaluate the effect of air entrapment, air vents of a certain size are added to the bridge structure and impact and uplift forces recalculated.

\section{LITRETURE REVIEW OF WAVE INTERACTING WITH BRIDGE DECK}

Most research on wave structure interaction utilizes laboratory experiments. El Ghamry (1963) investigated uplift and impact forces applied to a horizontal deck under periodic waves for variety of clearances distance between the deck and still water level using variety of wave heights and periods.

\footnotetext{
${ }^{1}$ Sonny Astani Department of Civil \& Environmental Engineering, University of Southern California, 3620 S. Vermont Ave., Los Angeles, CA, 90089-2531, USA

2 Department of Civil and Mechanical Engineering, California Institute of Technology, 1200 East California Boulevard Pasadena, CA, 91125, USA
} 
French (1969) researched the interaction between solitary waves and flat plate. He measured positive and negative uplift forces on a simple flat plate by means of experimental and analytical studies. Wang (1970) developed simple formulas to estimate maximum uplift pressure on a flat plate for various types of incident waves. Denson (1978) measured drag and lift and the rolling moment applied to a 1:24 scale model of St. Louis Bay, Mississippi bridge caused by incident waves. Kaplan at al. (1995) described theoretical analysis procedure for predicting wave impact forces acting on deck structure of offshore platforms in large incident waves. Douglass et al. (2006) conducted an extensive literature review related to hurricane wave forces on highway bridge superstructures. In their literature review, they concluded that existing methods to evaluate wave loads on highway bridge geometries were inadequate. Based on laboratory experimental data, Douglass et al. (2006) proposed a new empirical equation for estimating wave loads on bridge decks after concluding that none of the available methods would accurately predict the observed damage during Hurricanes Ivan and Katrina. Cuomo et al.(2007) measured wave forces and pressure on a 1:25 scale wooden deck with cross and longitudinal downstanding beams. The study showed that hydrodynamic forces depend on wave height, the clearance between the super structure and the still water level (SWL). The American Association of State Highway and Transportation Officials (AASHTO) have developed a series of equations to calculate design loads on coastal bridges due to waves. These equations are parameterization of a physical-based model derived from Kaplan's equations of wave forces originally developed for offshore oil platforms. The equations account for the bridge span design (slab vs. girder), as well as the type of girders used. The geometry of the bridge span is also considered, including girder depth, span width, and rail height. These equations also account for the effect of trapped air between girders through a trapped air factor (TAF) which is calculated and applied to the quasi steady vertical forces. The recommended application of the TAF allows designers to calculate a range of quasi-steady vertical forces, based on a minimum and maximum TAF.

Although available empirical equations from laboratory prototype experiments can be used to get approximate estimations of wave forces on bridge decks, they are usually derived from scaled laboratory experiments with simplified geometry that can be very different from the prototype bridge deck. Also, most empirical equations provide only maximum values of wave forces rather than the force time history. In addition, most empirical equations do not consider the effect of air entrapment. If they do consider air entrapment, they only provide the range of possible forces, which is sometimes very conservative and unrealistic.

In this regard, numerical modeling of wave loads on a full scale bridge deck using the actual deck geometry is a very useful supplementary approach for estimating wave loads. Few research studies on numerical modeling of wave forces on bridge decks exists in published literature. Iradjpanah (1983) and Lai (1986) developed a finite element procedure to investigate aspects of wave hydrodynamics on a horizontal platform. They validated their numerical simulation results through comparison with experimental data of French (1969). Patarapanich (1984) presented a general solution for wave reflection and transmission from fixed horizontal plate using the finite element method. His study covered a range of relative depth ratios from shallow to deep water limits, and submergence ratios from water surface to bed. He also extended the existing long wave solution for the surface and submerged plate, to obtain the hydrodynamic forces and overturning moment exerted on the plate. Baarholm and Faltinsen (2004) used a boundary-element model to study water impacts on a fixed horizontal platform deck from regular incident waves. They simplified this problem to a two dimensional potential flow problem and solved the resulting boundary value problem by three different numerical methods. Xiao and Huang (2008) used Reynolds averaged Navier-Stokes (RANS) - based numerical model to study waves breaking on a mild slope beach, and horizontal forces acting on a beach front house. However the model was not used to study uplift forces acting on bridge decks. Wenrui et al (2008) did numerical modeling of dynamic wave force acting on the Escambia Bay Bridge deck which was extensively damaged during Hurricane Ivan. He concluded that the maximum uplifting wave forces were larger than the weight of a simply supported bridge deck, causing direct damage to the bridge deck. He also made comparison of numerical modeling results to maximum wave forces obtained from empirical equations. He concluded that although empirical equations can provide a rapid estimate of maximum wave forces for preliminary risk analysis, numerical modeling is needed to produce details of time series dynamic wave forces to support coastal hazard assessment and bridge designs. He did not discuss the effects of air entrapment and entrainment on hydrodynamic forces and did not provide any guidelines which can help retrofit existing bridges or help in the design of new bridge structures. 


\section{ANALYSIS OF THE CAUSE OF BRIDGE FAILURE DURING RECENT HURRICANES}

Analysis of bridge failures during Hurricane Katrina indicated that the low elevation of the superstructure relative to the Mean Water Level (MWL) was a significant factor to bridge overall failure (Douglass et al., 2006; Chen et al., in press; Robertson et al., 2007). Historic storm surges during Hurricane Ivan and Katrina raised the water level to elevations that exceeded the low cords of the bridge girders (Douglass et al., 2004; Grumman, et al., 2005; Douglass et al., 2006). In cases where MWL exceeded the bottom of the super structure, the storm surge produced an uplift force due to buoyancy, which countered the dead weight of the structure. Buoyancy may have been enhanced by air pockets trapped between the girders and diaphragms. Figure 2 and Figure 3 show some major bridges that were damaged during recent Hurricanes.

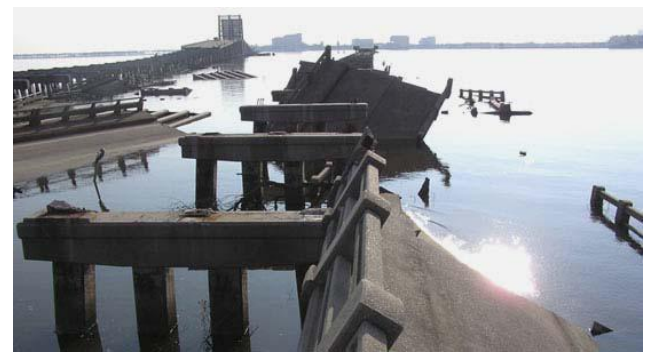

Figure 2. Damage to the U.S. 90 Biloxi Bay Bridge caused by Hurricane Katrina.

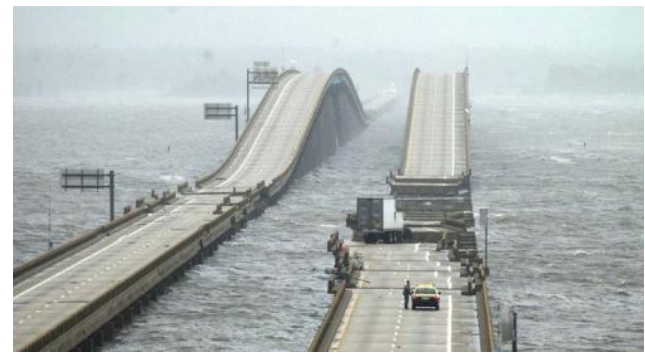

Figure 3. I-10 Bridge over Escambia Bay, FL after Hurricane Ivan.

Investigation of the failure mechanism for the bridges damaged during Hurricane Katrina theorized that the uplift force due to buoyancy combined with the horizontal and vertical hydrodynamic force due to impacting waves imposed a large enough force to overcome the weight of a bridge superstructure element and the capacity of any bent cap connections (Douglass et al., 2006; NIST, 2006)

There have not been many experiments or numerical simulations to address the importance of air entrapment on hydrodynamic forces even though it has been determined to be a major contributing factor to bridge overall failure. This paper will address the importance of air entrapment on amplification of hydrodynamic forces and will evaluate the efficacy of airvents in reducing hydrodynamic forces applied to bridges which are prone to coastal waves and currents.

\section{NUMERICAL MODEL}

The commercial CFD code STAR CCM+ was used as a tool to calculate hydrodynamic forces. In this section basic flow equations are presented. Finite Volume Method (FVM) is used to solve underlying governing equations. The starting point for FVM is the integral form of Navier Stokes equations:

$$
\begin{gathered}
\frac{d}{d t} \int_{V} \rho d V+\int_{S} \rho\left(\mathrm{v}-\mathrm{v}_{b}\right) \cdot n d S=0 \\
\frac{d}{d t} \int_{V} \rho u_{i} d V+\int_{S} \rho u_{i}\left(\mathrm{v}-\mathrm{v}_{b}\right) \cdot n d S=\int_{S}\left(\tau_{i j} i_{j}-p i_{i}\right) \cdot n d S+\int_{S} \rho b_{i} d V
\end{gathered}
$$

In these equations, $\rho$ is the fluid density, $V$ is the control volume (CV) bounded by a closed surface $S$. v is the fluid velocity vector whose Cartesian components are $\mathrm{u}_{i} . \mathrm{v}_{b}$ is the velocity of the CV surface, $t$ is time, $p$ is pressure, $b_{i}$ is the body force in the direction of the Cartesian coordinate $x_{i}, n$ is unit vector normal to $S$ and directed outwards, and $\tau_{i j}$ are components of the viscous stress tensor defined for Newtonian incompressible fluids as:

$$
\tau_{i j}=\mu\left(\frac{\partial u_{i}}{\partial x_{j}}+\frac{\partial u_{j}}{\partial x_{i}}\right)
$$

A typical 2D control volume is shown in figure 4. Then solution domain is then subdivided into finite number of CVs, which can be of any arbitrary shape. Conservation equations are applied to each $\mathrm{CV}$ and discretized in order to obtain one algebraic equation per $\mathrm{CV}$; each equation involves the unknown from the $\mathrm{CV}$ center and from a certain number of other CVs. The equation also needs to be linearized; this means that an iterative solution is used. The coupled system of equations is efficiently 
solved in a segregated manner which means when solved for each variable, other variables are treated as known.

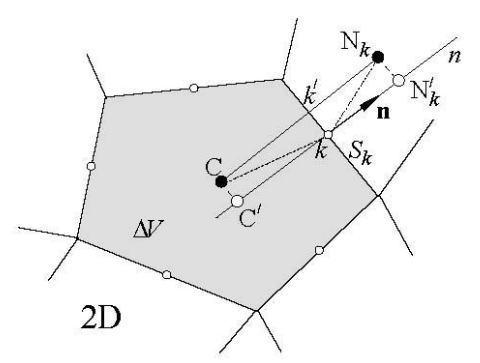

Figure 4. An example of 2D control volume.

FVM involves some levels of approximation: Integrals over surface, volume and time need to be evaluated by suitable numerical approximation, which uses the value of the integrand at one or more locations within the integration domain. Values at other locations which are required for evaluation of the integrals have to be obtained by interpolation; also, derivatives of certain quantities are required, which makes numerical differentiation necessary. Details about the discretization techniques used can be found in the large body of work by Ferziger and Peric(1996) and STAR-CCM+ documentation.

After equations (1) and (2) are discretized and the unknown variables and explicitly calculated are separated, an algebraic equation of the form:

$$
A_{C} \varphi_{C}+\sum_{K} A_{K} \varphi_{N_{K}}=Q_{C}
$$

is obtained for each $\mathrm{CV}$. The coefficients $\mathrm{A}_{\mathrm{K}}$ contain contributions from surface integrals over faces common to the cell around node $\mathrm{C}$ and the corresponding neighbors $\mathrm{N}_{\mathrm{K}} ; A_{C}$ contains additional contributions from the unsteady term. $Q_{c}$ contains all terms which are treated as known (parts of the unsteady terms and parts of surface integrals) and $\varphi_{c}$ is a conserved quantity. For the solution domain as a whole, the algebraic equation system can be written in matrix form as:

$$
A \Phi=Q
$$

Where $\mathrm{A}$ is a square $\mathrm{M} \times \mathrm{M}$ coefficient matrix and $\Phi$ is the vector of unknowns, $Q$ is the vector of right-hand sides, and $\mathrm{M}$ is the number of CVs. The Algebraic Multigrid method which solves the discrete linear system iteratively is used for solving equation (5).

For calculation of pressure, a pressure correction equation is constructed using discretized momentum and continuity equation. This solution approach is follows the SIMPLE algorithm and starts with a guessed pressure field. Each time the linearized momentum equations are solved, the mass conservation is imposed on the new velocities by applying a velocity correction, which is proportional to the gradient of the pressure correction, as dictated by momentum equations.

\section{BOUNDARY AND INITIAL CONDITIONS}

The initial fields of all variables are known and satisfy all the equations. In addition boundary conditions also need to be prescribed at all future times. This means that surface integrals over cell faces within in the solution domain boundary are calculated using prescribed boundary data. The implementation of these conditions in FVM is described in detail in many standard computational fluid dynamic books and will not be repeated here. Four kinds of boundary conditions are used in this study and are shown in Figure 5.

1. Wall

2. Velocity Inlet

3. Pressure Outlet

4. Symmetry Plane

For the wall boundary condition, the normal velocity is explicitly set to zero. The boundary face pressure is extrapolated from the adjacent cell using reconstruction gradients.

For the velocity inlet boundary condition, the inlet face velocity vector is specified directly. The boundary face pressure is extrapolated from the adjacent cell using reconstruction gradients. 
For the pressure outlet, the boundary face velocity is extrapolated from the interior using reconstruction gradients and the boundary pressure is specified.

For the symmetry plane shear stress at a symmetry boundary is zero the face value of velocity is computed by extrapolating the parallel component of velocity in the adjacent cell using reconstruction gradients. The boundary face pressure is extrapolated from the adjacent cell using reconstruction gradients.

The free surface does not represent a boundary and no boundary condition needs to be prescribed at it. Volume of Fluid (VOF) is adopted to prescribe dynamic free surface which is capable of modeling complex free surface shapes including breaking waves. The solution domain extends over both air and water and the conservation equations are solved in the whole domain. Both fluids are treated as a single effective fluid, whose properties vary in space according to volume fraction of each phase, i.e.:

$$
\rho=\rho_{1} c+\rho_{2}(1-c) \quad \mu=\mu_{1} c+\mu_{2}(1-c)
$$

Where $0 \leq c \leq 1$ is volume fraction and its change is governed by the transport equation as:

$$
\frac{d}{d t} \int_{V} c d V+\int_{S} c\left(\mathrm{v}-\mathrm{v}_{b}\right) \cdot n d S=0
$$

Subscripts 1 and 2 in equation (6) denote the two fluids (e.g. liquid and gas). If one CV is partially filled with one and partially filled with the other fluid (i.e. $0 \leq c \leq 1$ ) it is assumed that both fluids have the same velocity and pressure. In addition, for air, which is considered compressible, pressure and density are related through ideal gas law and at each time step values of density are updated according to the new pressure.

At the location of the wave maker, the wave surface displacement and particle velocities are specified based on the Boussinesq (1872) approximation for a solitary wave as follows:

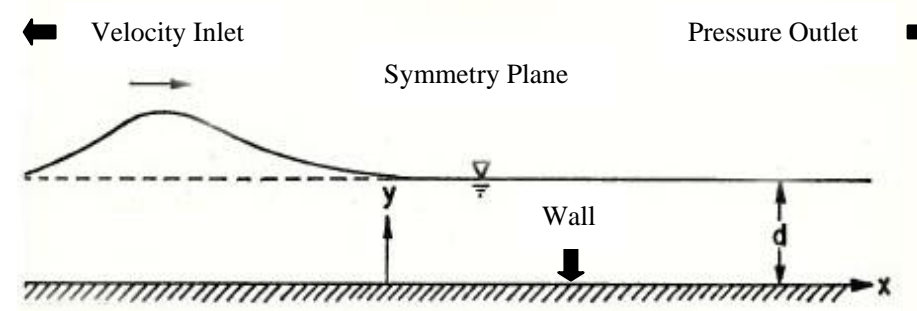

Figure 5. Solitary wave profile

$$
\begin{aligned}
& \eta(x, t)=H\left(\operatorname{sech} \sqrt{\frac{3 H}{4 d}} \frac{X}{d}\right)^{2} \text { where } \mathrm{X}=\mathrm{x}-\mathrm{ct} \\
& \mathrm{c}=\sqrt{g(d+H)} \\
& \frac{u}{\sqrt{g d}}=\frac{\eta}{d}\left\{1-\frac{\eta}{4 d}+\frac{d}{3}\left(\frac{d}{\eta}\right)\left[1-\frac{3}{2}\left(\frac{y}{d}\right)^{2}\right] \frac{d^{2} \eta}{d x^{2}}\right\} \\
& \frac{v}{\sqrt{g d}}=\frac{y}{d}\left\{\left(1-\frac{1}{2} \frac{\eta}{d}\right) \frac{d \eta}{d x}+\frac{d^{2}}{3}\left(1-\frac{1}{2} \frac{y^{2}}{d^{2}}\right) \frac{d^{3} \eta}{d x^{3}}\right\}
\end{aligned}
$$

In the above equations, $\eta(x, t)$ is wave profile, $\mathrm{c}$ is wave speed, $\mathrm{H}$ is wave amplitude, and $u$ and $v$ are water particle velocities in $\mathrm{x}$ and $\mathrm{y}$ direction respectively.

\section{MODEL VALIDATION FOR UPLIFT FORCE ON A HORIZONTAL PLATFORM}

In this study, model validation was conducted by comparing with laboratory experiments before it was applied to I-10 bridge superstructure. French's (1969) experimental results of a solitary wave 
interacting with a simple flat plate are used for this validation. The experimental setup is presented in Figure 6. The still water depth is $d=15 "$, the width of rectangular structure is $L=4 d=60 "$, the distance between the bottom of the rectangular structure and the still water surface is $\mathrm{s}=0.2 \mathrm{~d}=3$ ".

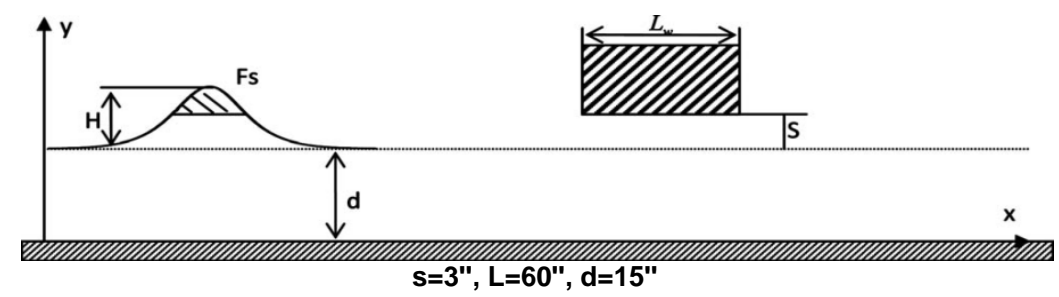

Figure 6. Experimental setup (French 1969) for numerical model validation (Fs=weight of water in approaching solitary wave above platform marked as shaded water area; $d=$ water depth)

Three test cases were conducted with incident wave heights $\mathrm{H}=0.24 \mathrm{~d}, 0.32 \mathrm{~d}$ and $0.4 \mathrm{~d}$ respectively. Wave forces on the rectangular structure were calculated through model simulation under the incident solitary waves with the same wave heights and periods as the experimental data. To choose the right mesh size and time step model sensitivity studies have been conducted under different mesh sizes and time step. In order to save computational time an anisotropic mesh is used and mesh size varied from $\Delta \mathrm{x}=\Delta \mathrm{y}=1.25 \mathrm{~cm}$ to $\Delta \mathrm{x}=\Delta \mathrm{y}=2.5 \mathrm{~cm}$ and time step $\Delta \mathrm{t}=0.001 \mathrm{~s}$ is used to provide the stable precise solution during the entire computation. Figures 7 to 9 show comparison of the vertical wave force when the ratio of wave height and water depth is $0.24,0.32$ and 0.4 respectively along side with two other simulation results based on finite element code by Iradjpanah (1983), Lai (1986) and Lai \& Lee(1989). In general, results show good agreement between model predictions of uplift forces and experimental data for all three cases. In addition, the current finite volume code seems to do a better job of predicting uplift forces compared to other simulation results based on finite element simulations.

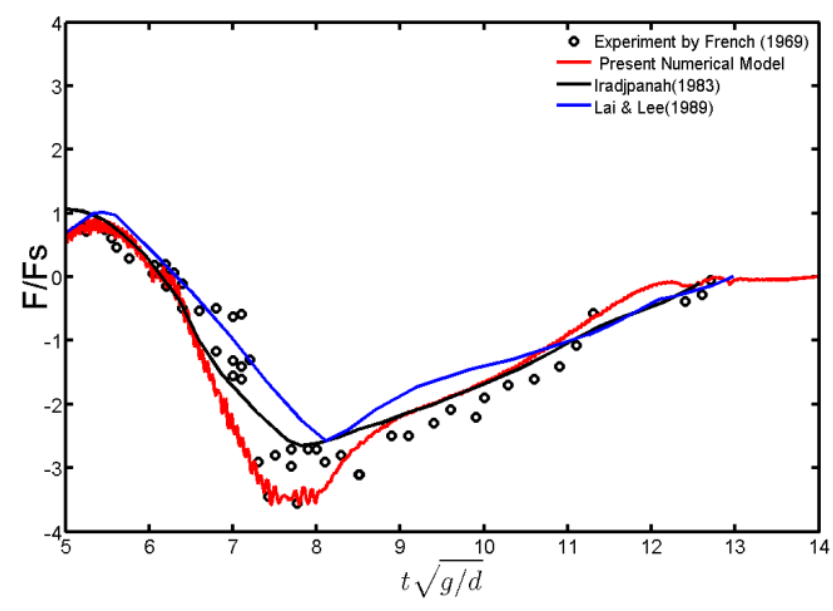

Figure 7. Ratio of wave height to depth $\mathrm{H} / \mathrm{d}=0.24$ 


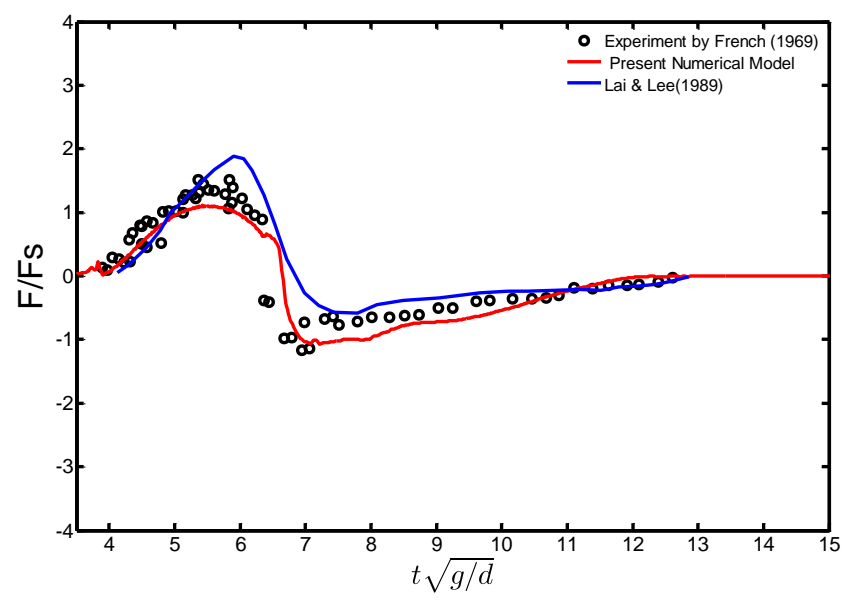

Figure 8. Ratio of wave height to depth $\mathrm{H} / \mathrm{d}=0.32$

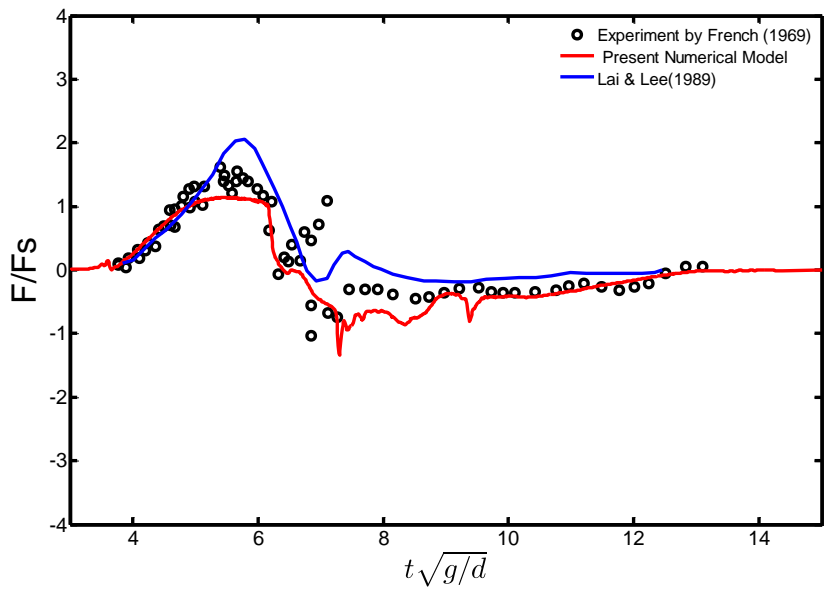

Figure 9. Ratio of wave height to depth $\mathrm{H} / \mathrm{d}=0.4$

\section{DYNAMIC WAVE LOADING ON A BRIDGE SUPER STRUCTURE}

The validated model was applied to investigate the dynamic wave loads on a bridge geometry similar to the I-10 Bridge across Mobil Bay. The cross section for unit length of the continuing bridge deck is simplified to a two dimensional computational domain, as shown in Figure 10. The bridge geometry dimensions, water depth $\mathrm{d}$, and distance between the lowest part of bridge structure and water surface $s$ are also shown in Figure. 10 and are kept constant throughout all simulation cases. Figure 12 shows the mesh used in simulation. In order to increase computational efficiency and reduce computational time, anisotropic mesh is used in these simulations with mesh size varying from $0.6 \mathrm{~m}$ to $0.03 \mathrm{~m}$.

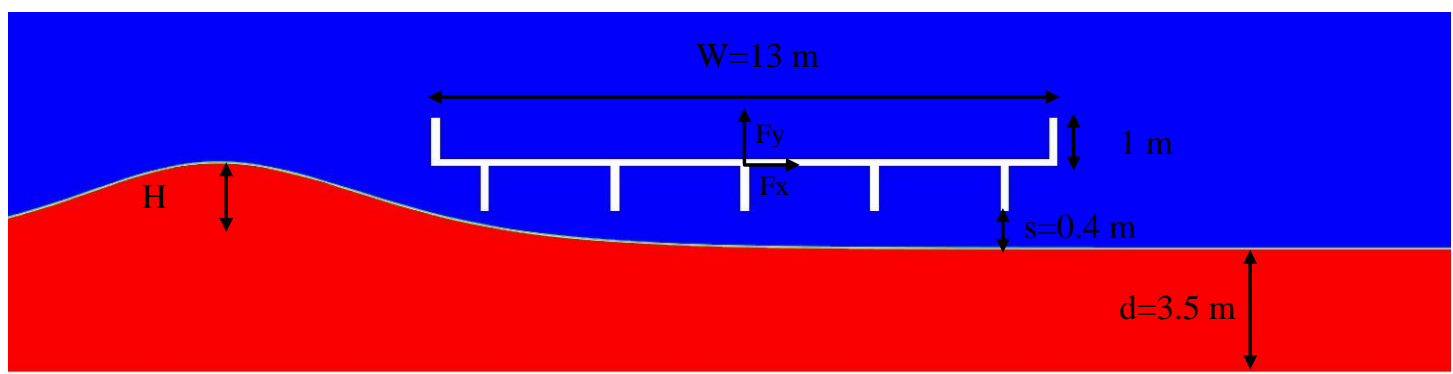


Figure 10. Model setup for simulating wave-bridge interaction

At the wave forcing boundary, a solitary wave generated using equation (8) as the initial condition propagating from left to right to approximate shallow water waves. The fixed time step $\Delta \mathrm{t}=0.003 \mathrm{~s}$ is used to provide a stable precise solution during the entire computation. Figure 12 shows some snapshots of these simulations. In these figures, blue represents air, red represents water and other colors in between represent mixture of air and water.

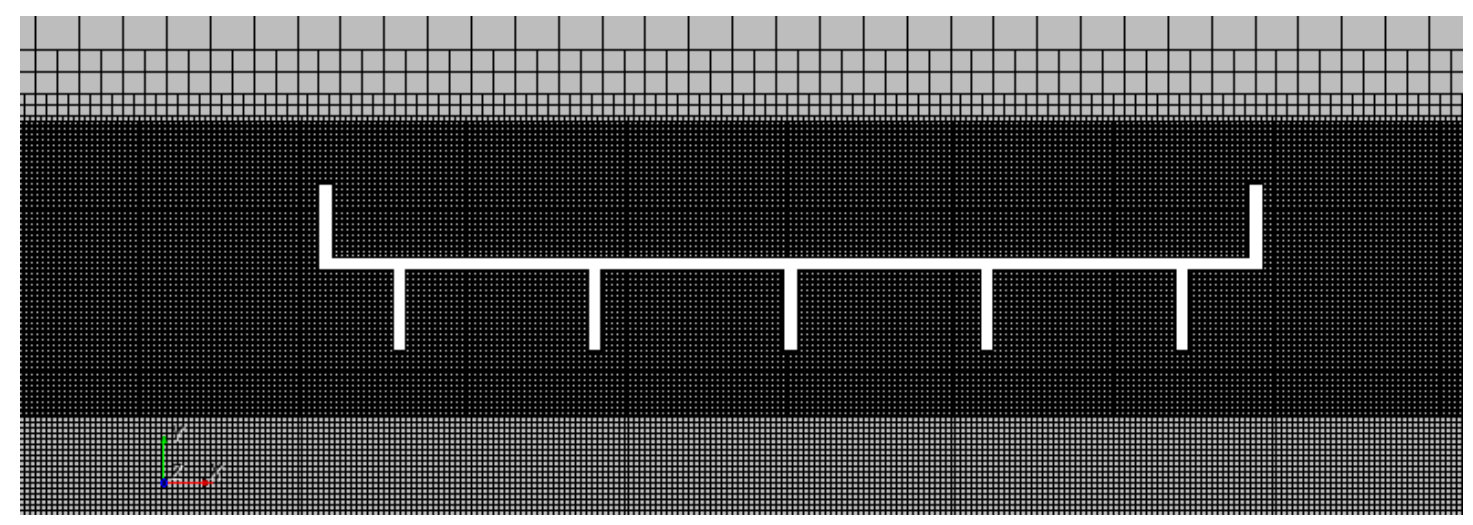

Figure 11. Anisotropic mesh used in simulation

The total vertical force time history is shown in Figure 13 for different ratios of s/H. For the majority of $\mathrm{s} / \mathrm{H}$ ratios the vertical force time history consists of a short duration impulsive load followed by quasi-static positive and quasi-static negative loads. The dash line in Figure 8 represents the weight of bridge superstructure per unit width. As evident in this figure, for s/ $\mathrm{H}$ ratio of 0.23 which corresponds to wave amplitude of $\mathrm{H}=1.74 \mathrm{~m}$, between $\mathrm{t}=1.9 \mathrm{~s}$ and $\mathrm{t}=2.2 \mathrm{~s}$, the vertical quasi-static force is above the weight of bridge deck. As a result, the weightless deck lifted by the vertical force can be easily moved away under the action of the horizontal forces.
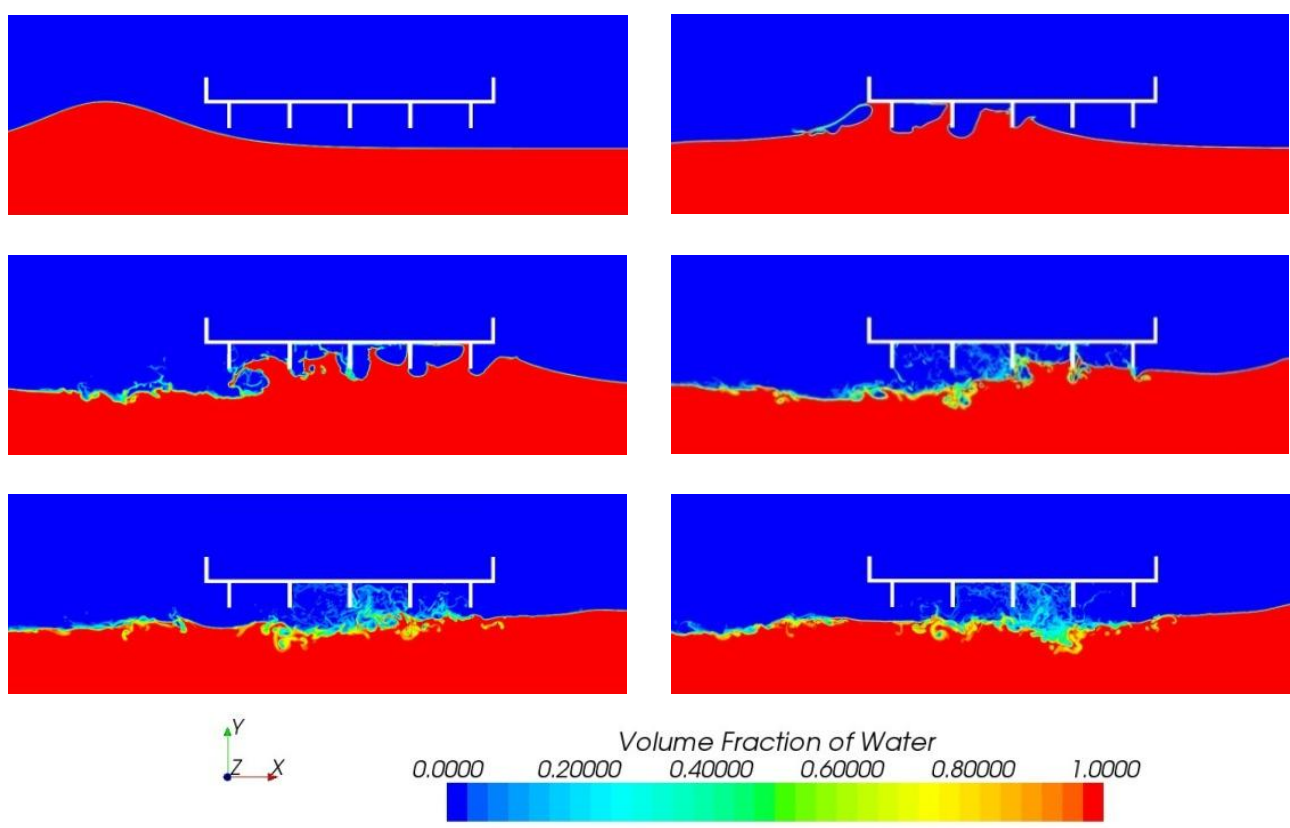

Figure 12. Wave interacting with bridge deck

Figure 14 shows the time history of horizontal forces for different ratios of s/H. Horizontal forces seem to have a similar pattern as vertical forces, consisting of short duration impulsive load, quasi- 
static positive, and quasi-static negative forces. For horizontal force time history, the magnitude of impulsive load is up to 2.5 times bigger than the quasi-static positive force (for $\mathrm{s} / \mathrm{H}=0.23$ ) while in the vertical force time history, the magnitude of impulsive load is almost equal to the magnitude of quasi-static positive force (for $\mathrm{s} / \mathrm{H}=0.23$ ) or less than quasi-static positive force(for other cases). Not a lot of information is available in literature regarding importance of the short duration impulsive load and its influence on overall failure of bridge super structure during recent Hurricanes. At this point, it is obvious from force time history that the existence and magnitude of these impulsive forces depend on wave velocity and magnitude and can be related to the entrapment of air beneath the bridge super structure.

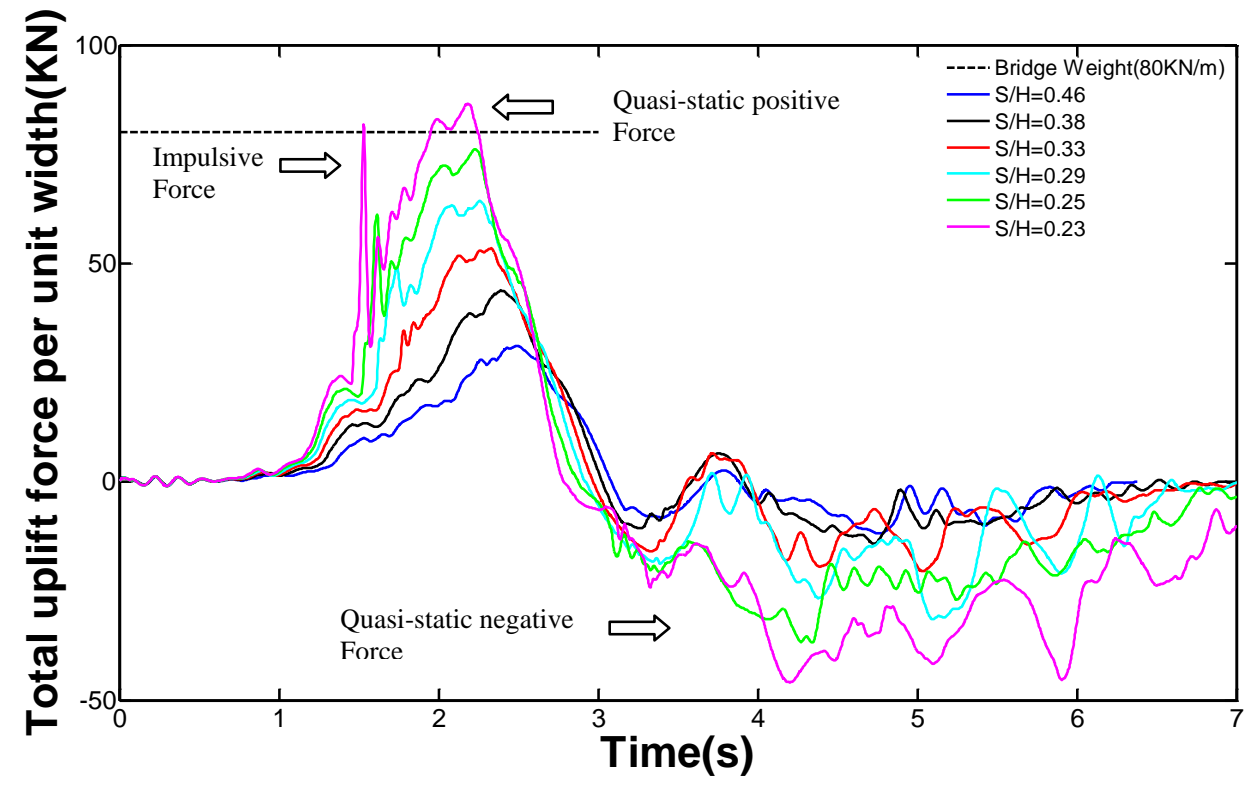

Figure 13. Total uplift force per unit width

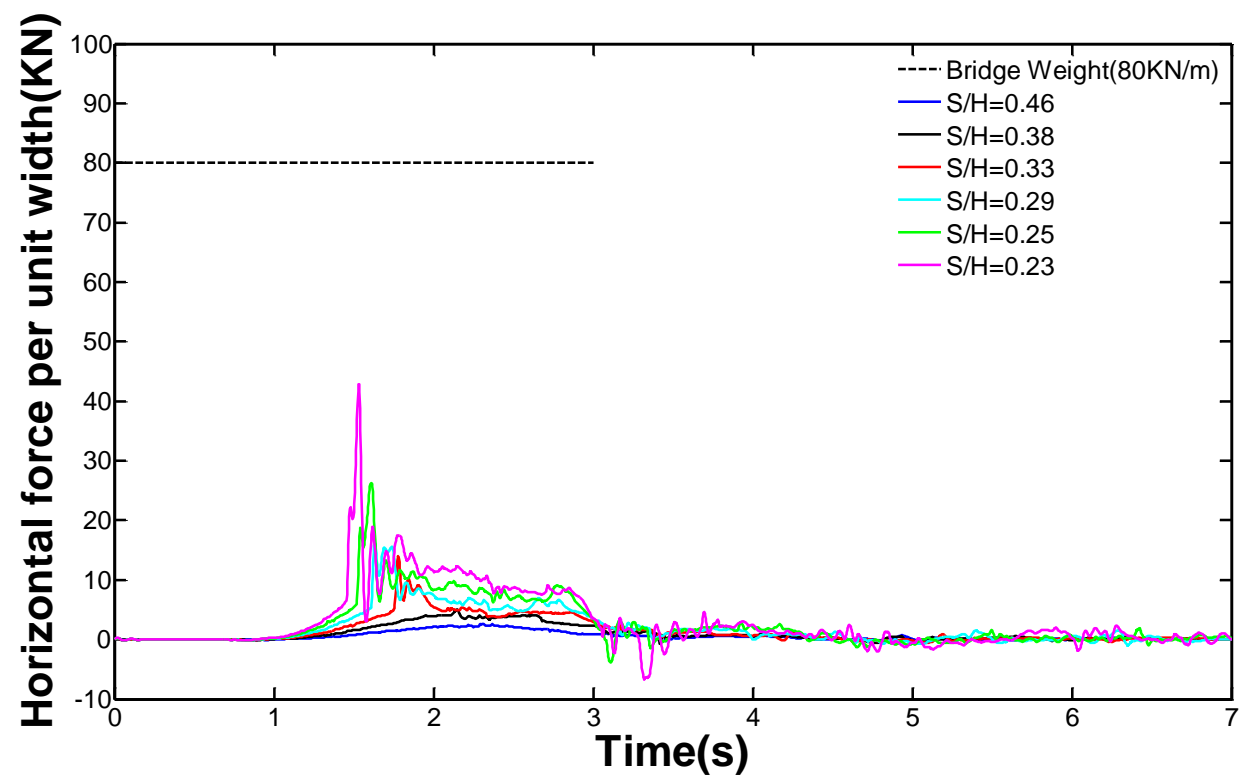

Figure 14. Total horizontal force per unit width

\section{ROLE OF ENTRAPPED AIR ON WAVE UPLIFT AND IMPACT FORCES}

In order to assess the effect of air entrapment on hydrodynamic forces, airvents modeled in the bridge deck. The initial size considered for these airvents occupy about one percent of total deck area 
or $0.005 \mathrm{~m}^{2} / \mathrm{m}^{2}$. Because the current model is two dimensional airvents are modeled as $0.01 \mathrm{~m}$ width slits which are continuous along the width of bridge super structure (Figure 15).

The current model was applied to the bridge retrofitted by airvents and simulations were carried out for similar wave conditions as the case without airvent. Figure 16 shows simulation results for total vertical hydrodynamic forces applied to bridge super structure. As it is evident from this figure, uplift forces were reduced significantly compared to the case where airvents were not used. It also shows that the maximum uplift force does not exceed the weight of bridge span which means the bridge would not incur any significant damage after being retrofitted with airvents.

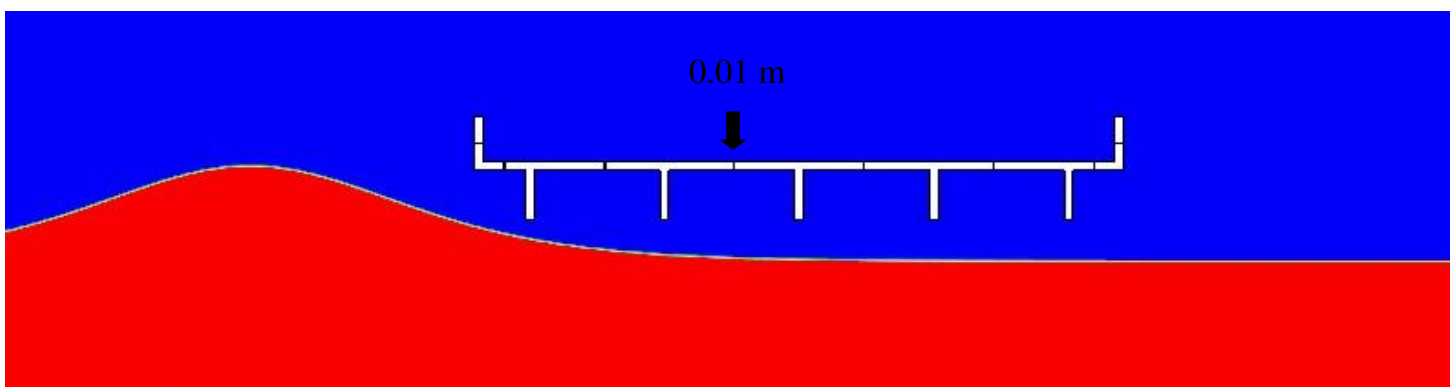

Figure 15. Location of air vents used for retrofitting bridge super structure.

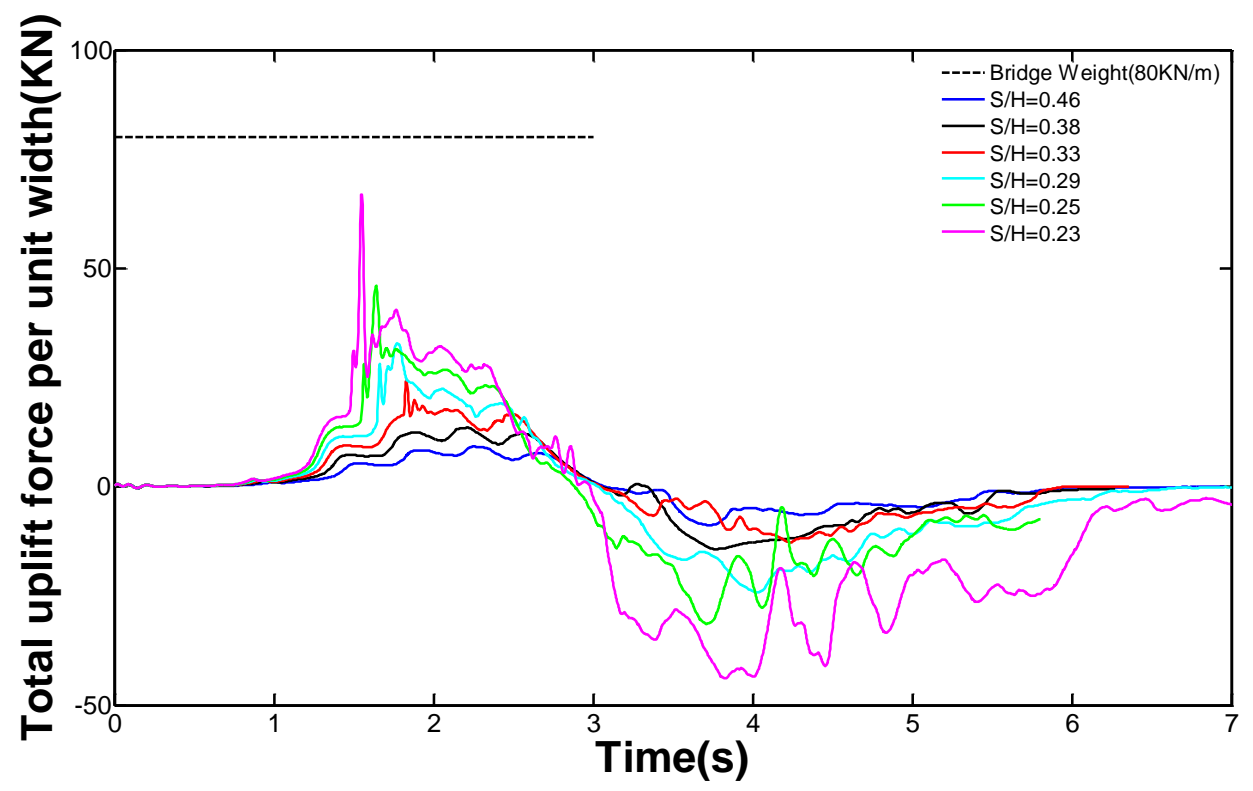

Figure 16. Total uplift force per unit width for retrofitted bridge

Figure 17 shows the effect of airvents on vertical forces for different ratios of s/H. As is evident from this figure, airvents reduce both short duration impulsive and longer duration quasi-static positive forces. Airvents seem to be more effective in reducing quasi-static forces, which according to literature are considered the main cause for bridge failure. The degree of efficacy of these airvents in reduction of vertical forces seem to depend on wave amplitude, wave velocity and the air gap s which is related to the amount of air that gets trapped under bridge superstructure. Current simulation results shows that airvents are able to reduce quasi-static positive forces from $53 \%$ to $71 \%$.

Airvents also seem to reduce the magnitude of negative forces (downward forces) for the majority of simulation cases. In addition, Wave crests decay more rapidly for the cases with the airvent while waves seem to conserve their energy traveling around the decks without airvents. In addition, force time history plot with airvent shows less oscillatory behavior when compared with the case without airvent.

The current configuration of airvents does not seem to influence horizontal hydrodynamic forces. It is still a good topic of research to check other airvent configurations such as airvents being located in bridge girders and their influence on horizontal forces. 

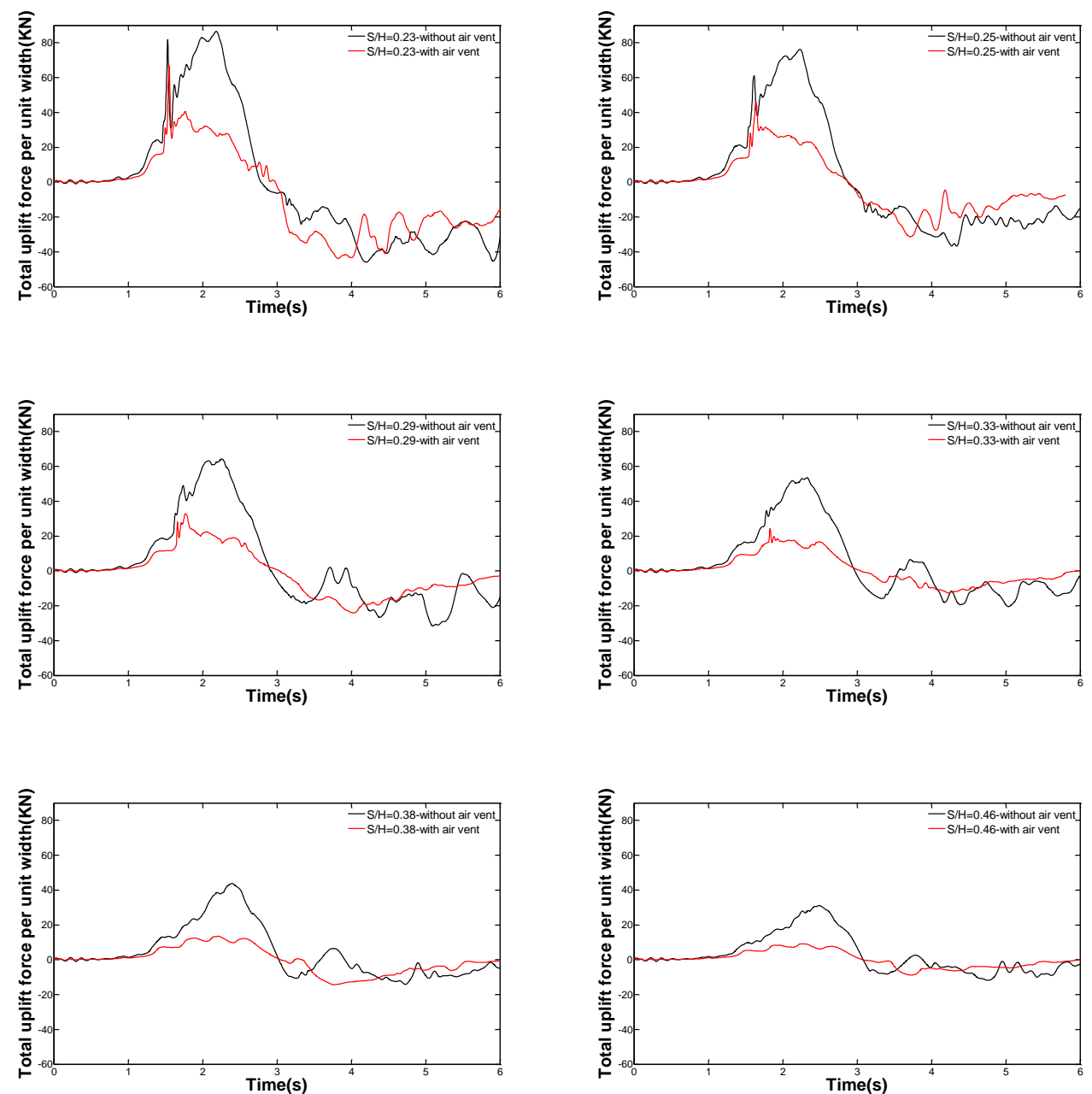

Figure 17. Total uplift force per unit width for retrofitted bridge

\section{Conclusion}

The numerical wave-load model based on Navier Stokes type equations and the VOF method has been applied to investigate the dynamic impact of wave forces on a bridge deck similar to I-10 bridge across Mobil Bay damaged by Hurricane Katrina. The model has been validated by comparison with laboratory experiments of French (1969) for uplift wave forces on a horizontal platform.

Numerical simulations were carried out for different ratios of $\mathrm{s} / \mathrm{H}$ ranging from 0.23 to 0.46 with fixed clearance distance of $\mathrm{s}=0.4 \mathrm{~m}$ and fixed water depth of $\mathrm{d}=3.5 \mathrm{~m}$. The total force time history of solitary wave interacting with a bridge deck for the majority of $\mathrm{s} / \mathrm{H}$ ratios consisted of short duration impulsive load followed by quasi-static positive and quasi-static negative forces. Simulation results indicate that for $\mathrm{s} / \mathrm{H}$ ratio of 0.23 which corresponds to wave amplitude of $\mathrm{H}=1.74 \mathrm{~m}$, maximum uplift force was greater than the weight of the bridge deck. As a result the simply supported bridge deck could be lifted by the vertical wave force and subsequently moved away by the horizontal wave force.

In order to evaluate the effect of air entrapment on hydrodynamic forces, airvents were modeled in the deck of bridge superstructure. Numerical simulation was carried out for exactly the same wave condition as the bridge without airvents. It has been shown that the current configuration and size of airvents can significantly reduce vertical hydrodynamic forces for all ratios of s/H. As a result, airvents can be used as an effective mean to retrofit existing bridge structures that are prone to coastal currents and waves and can be incorporated in design of future hydraulic structures. 


\section{REFERENCES}

AASHTO. (2008). Final Draft: Guide Specifications for Bridges Vulnerable to Coastal Storms (BVCS1). Washington, DC: American Association of State Highway and Transportation Officials.

Baarholm, R., and Faltinsen, O. M. 2004. "Wave impact underneath horizontal decks." J. Mar. Sci. Technol., 92, 1-13.

Boussinesq J. (1872). "Théorie des ondes et des remous qui se propagent le long d'un canal rectangulaire horizontal, en communiquant au liquide contenu dans ce canal des vitesses sensiblement pareilles de la surface au fond". Journal de Mathématique Pures et Appliquées, Deuxième Série 17: 55-108.

Cuomo, G., Allsop, W., and McConnell, K. 2003. "Dynamic wave loads on coastal structures: Analysis of impulsive and pulsating wave loads." Coastal Structures 2003-Proc., Conf., Portland, Ore., ASCE, 356-368.

Denson, K. H. 1978. "Wave forces on causeway-type coastal bridges." Water Resources Research Institute, Mississippi State Univ., Mississippi State, Miss.

Douglass, S. L., Chen, Q., and Olsen, J. M. 2006. "Wave forces on bridge decks." Coastal Transportation Engineering Research and Education Center, Univ. of South Alabama, Mobile, Ala.

Douglass, S. L., Hughes, S., Rogers, S., and Chen, Q. 2004. "The impact of Hurricane Ivan to the coastal roads in Florida and Alabama: A preliminary report." Rep. to Coastal Transportation Engineering Research and Education Center, Univ. of South Alabama, Mobile, Ala.

El Ghamry, O. A. 1963. "Wave forces on a dock.” Technical Rep. No.HEL-9-1, Hydraulic Engineering Laboratory, Institute of Engineering Research, Univ. of California, Berkeley, Calif.

Ferziger, J.H. \& Peric, M., Computational Methods for Fluid Dynamics, Springer, Berlin, 1996.

French, J. A. 1969. "Wave uplift pressure on horizontal platforms.” Rep. No. KHR19, W. M. Keck Laboratory of Hydraulics and Water Resources, California Inst. of Technology, Pasadena, Calif.

Hirt, C. W., and Nichols, B. D. 1981. "Volume of fluid VOF method for the dynamics of free boundaries.” J. Comput. Phys., 391, 201-225.

Iradjpanah, K., "Wave uplift pressure on horizontal platforms", PhD thesis, University of Southern California.

Kaplan, P., Murray, J. J., and Yu, W. C. 1995. "Theoretical analysis of wave impact forces on platform deck structures." Proc., Int. Conf. on Offshore Mechanics and Arctic Engineering, Copenhagen, Denmark, 1A, ASME, New York, 189-198.

Lai, C.P., 1986. "Wave interaction with structure: hydrodynamic loadings on platforms and docks.", PhD thesis, University of Southern California.

Lai, C.P. \& Lee, Jiin-Jen (1989) "Finite Amplitude Wave Uplift on Platforms or Docks" Journal of Waterways, Ports, Coastal \& Ocean Engineering, ASCE Vol. 115, No. 1, PP 19-39.

NIST. (2006). Performance of Physical Structures in Hurricane Katrina and Hurricane Rita: A Reconnaissance Report. Gaithersburg, MD: National Institute of Standards and Technology.

Patarapanich, M. 1984. "Forces and moment on a horizontal plate due to wave scattering." Coastal Eng., 83, 279-301.

STAR CCM+ software manual, CD-adapco, 2010.

Technical Lifelines Council for Earthquake Engineering TCLEE, 2006. "Hurricane Katrina: Performance of transportation systems." R. Des Roches, ed., ASCE Technical Council on Lifeline Earthquake Engineering Monograph No. 29, American Society of Civil Engineers, June.

Wang, H. 1970. "Water wave pressure on horizontal plate.” J. Hydr. Div., 9610, 1997-2017.

Xiao, H., and Huang, W. 2008. "Numerical modeling of wave runup and forces on an idealized beachfront house." Ocean Eng., 35, 106-116. 